\title{
Integración de las metodologías Building Information Modeling 5D y Earned Value Management a través de una herramienta computacional Building Information Modeling,5D and Earned Value Management methodologies computational tool integration
}

\author{
C. Cárdenas *, P. Zapata ${ }^{1}$, N. Lozano *
}

Fecha de Recepción: 11/01/2018

Fecha de Aceptación: 27/04/2018

PAG 263-278

\section{Abstract}

Many construction projects present uncertainty in their budgets and schedules. Also, the management of time and costs is inconsistent. There are methodologies and techniques that improve the management of construction projects: Techniques such as Earned Value Management (EVM), ideal for planning, monitoring and controlling the management of time and costs during the execution of projects, and methodologies such as Building Information Modeling (BIM) recognized for improving the planning and design of construction projects. This paper proposes the integration of BIM and EVM through an OpenBIM software called COST-BIM, designed in JAVA programming language and NetBeans 8.0.1 development environment. It manages construction projects time and costs under a single interface, consisting of four modules and fifteen processes. The software is validated through a real project of social interest housing (Vivienda de Interés Social VIS), comparing the budget, schedule, EVM original indicators and EVM projections of the project versus those generated by the tool.

COST-BIM manages construction projects from its planning, during its execution and until its monitoring and control turning it into a useful software for construction managers that strive to increase the performance of their projects.

Keywords: Building Information Modeling, Earned value management, Schedule control, Costs control, Progress curves

\section{Resumen}

Muchos proyectos de construcción presentan incertidumbre en sus presupuestos y cronogramas. Asimismo, el manejo de tiempo y costos es inconsistente. Existen metodologías y técnicas que mejoran la gestión de proyectos constructivos: Técnicas como Gestión del Valor Ganado (EVM), ideal para planear, monitorear y controlar la gestión de tiempo y costos durante la ejecución de proyectos, y metodologías como Building Information Modeling (BIM) reconocida por mejorar la planeación y diseño de proyectos de construcción. Esta investigación propone la integración de BIM y EVM mediante un software OpenBIM Ilamado COST-BIM, diseñado en lenguaje de programación JAVA y entorno de desarrollo NetBeans 8.0.1. Gestiona tiempo y costos de proyectos constructivos bajo una única interfaz, conformada por cuatro módulos y quince procesos. La herramienta se valida a través de un proyecto real de Vivienda de Interés Social (VIS), comparando el presupuesto, cronograma, indicadores EVM y proyecciones EVM originales del proyecto frente a los generados por el software.

COST-BIM gestiona proyectos de construcción desde su planeación, durante su ejecución y hasta su seguimiento y control convirtiéndolo en un software útil para gestores de construcción que se esfuerzan por aumentar el rendimiento de sus proyectos.

Palabras clave: Building Information Modeling, Gestión del Valor Ganado, Control de presupuesto, Control de Costos, Curvas de Progreso

\section{Introduction}

Construction companies who have managed building projects know that they usually take more time and money than initially planned (Abadie et al., 2013). Therefore, construction managers are interested in managing and controlling their schedules and budgets in order to reduce costs and maximize profits (Hitt et al., 2006). However, preparing them requires collecting large amounts of data from different professionals, who generally do not interact nor communicate efficiently among them during the design phase of project deliverables, thereby entailing incompatibilities and data leaks and reprocessing during their integration process. This produces uncertainties in the quantification of resources (materials, labor and equipment) associated to the deliverables that will define the schedule and planned budget, which subsequently causes variations between the schedule,

\footnotetext{
1 Corresponding author:

Pontificia Universidad Javeriana, Bogotá, COLOMBIA

E-mail: paola_zapata@javeriana.edu.co
}

and the planned and executed budget of the project.

But uncertainty in the schedule and planned budget is not the only cause of variations between the schedule and the planned and executed budget in construction projects. According to (Abadie et al., 2013), this is only one of several causes, and add that the most common ones are: bad planning, inappropriate definition of the project's objectives and scope, poor communication among the professionals involved, ineffective project management and supervision, unsuitable identification of the project risks and deficient systems for estimating and controlling the project time and costs.

Furthermore, they add that the issue of budget and schedule variations is present at global level. They analyzed 975 building projects and found that only $5.4 \%$ of the projects were within budget, and $36.4 \%$ incurred in cost overruns above $50 \%$ of the planned budget. These data demonstrate the impact of the variations between the schedule and the planned and executed budget on the 
project's final cost. However, this phenomenon is not inherent to the planning phase. During the execution phase, there are often delays which cause cost overruns, because there is no system controlling the performance of the work actually completed (Abadie et al., 2013).

Based on the above, the variation between the schedule and the planned and executed budget of the construction industry projects, lies in the absence of a system that integrates the necessary tools to manage this kind of projects, from its planning and design stage to its execution, tracking and control in a single interface. Nevertheless, technology is radically changing the building management practices. Nowadays, there are methodologies like the Building Information Modeling (BIM) and techniques like the Earned Value Management (EVM), which are capable of managing construction projects from the planning and design stages to their execution, tracking and control, respectively.

The aforesaid clearly implies the need to reduce the variations between the planned and executed schedule and budget of construction projects. Consequently, using techniques like EVM, perfect for monitoring and controlling time and cost management during the projects' execution (Project Management Institute, 2005), and BIM methodology, recognized for improving the planning and development of construction projects, this research developed the BIM-EVM integration by creating a software called COST-BIM. This software aims at improving the management of construction projects' schedule and budget, within an interoperable virtual environment for planning, design, execution, tracking and control of building projects. This tool allows integrating the BIM methodology and the EVM technique on a single interface, thanks to its interoperability with OpenBIM tools, with the purpose of getting the best of the benefits of each one in the construction project management, and offering building managers a tool that helps them control the schedule and budget of their projects.

\section{Background}

(Stevens, 1986) proposed a project management tool based on the performance curve, integrating the project cost and time. (Miyagawa, 1997) set forth a construction manageability planning system (CMY Planner). (Eastman et al., 2008) introduced BIM as a more integrated design and construction process, whose goal is to produce better quality buildings at a lower cost. (Enshassi and Abuhumra, 2016) perceive the BIM benefits in the design phase, because collaborative tasks are performed among all stakeholders from the very beginning of the project; therefore, each aspect of the design can be coordinated. Other authors add that any change made in the design is reflected on the entire model, thus eliminating errors and saving time when changing the design drawings and models. (Staub-French and Khanzode, 2007) set out that the adoption of the $4 D$ model allows linking a programming to $3 D$ elements, thereby producing a constructive simulation. They state that the benefits are multiple: identification of conflicts in the design phase, productivity, less change orders, better cost control, and detection of building interferences. (Chou, Chen, Hou and Lin, 2010) established the need to display the project information visually and automatically for an efficient control process of the project. (Isaza et al., 2015) indicate that BIM reduces the risks by $66 \%$, improves the collaborative work among professionals by $63 \%$, reduces data reprocessing by $60 \%$, reduces the design time by $48 \%$, increases productivity by $67 \%$, and integrates the processes inside the organization by $75 \%$.

The mentioned authors deduce that BIM on its own is not enough to manage constructive projects during their entire life-cycles, especially because its greatest potential is reflected during the design stage for preparing building models and not during the execution, tracking and control stages.

On the other hand, (Czarnigow, 2008) analyzes the implementation problems of the EVM technique. He recommends the use of technologies or programming to achieve its successful implementation and make the most of its overall potential. Considering this, many researchers developed methods to get the benefits of the EVM technique. (Kim, 2009) evaluated the EVM in residential projects and analyzed the importance of the Cost Performance Index (CPI) and the Schedule Performance Index (SPI), and introduced a framework for assessing these indicators and how to use them to improve the project performance.

Based on the above, authors like (Jrade and Lessard, 2015) propose an integrated time and cost management system, called (ITCMS). It is composed by an EVM platform developed in Microsoft Excel and MS Project, which synchronizes the construction model with the project's time and cost parameters. The project's 3D BIM model was developed in Autodesk Revit 2013 and Autodesk Quantify Takeoff. The time for the activities is allocated in the MS Project to establish cost estimates and integrate these data into a Microsoft Excel datasheet to generate EVM curves in MS Project.

(Su et al., 2015) developed a model aimed at objects prepared in MS Virtual \#, called (CSIS), which links BIM elements to their respective costs and programming times, automatically calculates total project costs and time and exports this information to a MS Project or Primavera Project Planner.

Consequently, it has been demonstrated that BIM improves project management in the design and planning stages. Moreover, it was found that EVM is a useful tool, which allows a proper time and cost supervision and control, in accordance with the scope of the project, so that building managers can compare the progress of the planned baseline and then evaluate if their construction will meet the budget and schedule objectives. Therefore, a BIM-EVM integration through COST-BIM is proposed.

\section{Development of COST-BIM Software}

The COST-BIM software was developed in a model aimed at objects and programmed in NetBeans, a powerful integrated development environment for generating applications in the Java platform. Its development required the creation of IDE Project, a group of Java source code files, in addition to the associated metadata, the files with specific project characteristics and the compiling script that controls the compilation and execution configuration to run the tool. Figure 1 details the software components and its graphic interface. 

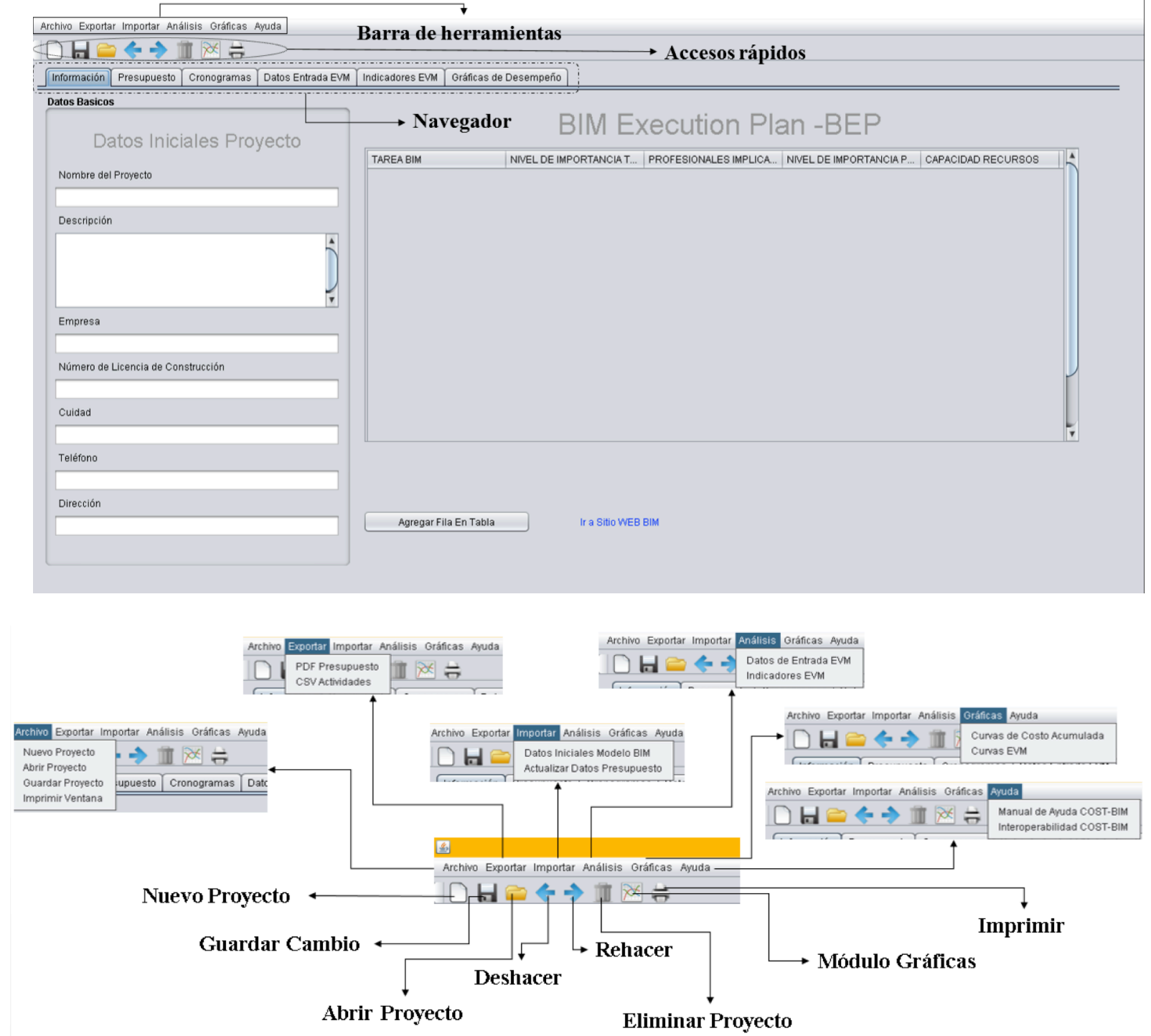

Figure 1. COST-BIM interface

COST-BIM was created with the idea of integrating BIM and EVM technologies; therefore, its interface was developed according to project management processes: planning, execution, tracking and control, and in turn, in accordance with a BIM Execution Plan framework (BEP). The development of this plan enables data management during the project and is based on the recommendations of the BIM Project Execution Planning Guide (Messner, 2010).

COST-BIM is an OpenBIM software that manages construction projects in a BIM-EVM system, prevents data leaks and reprocessing, automatically generates and updates the budget imported from a 5D BIM model (with unit quantities and values). Additionally, it exports the schedule data to other BIM tools for the simulation (4D), and makes
EVM analysis by generating project indicators and estimates by activity, based on trends.

\subsection{BIM-EVM System}

The BIM-EVM System is achieved through the COSTBIM interoperability with other OpenBIM software. Figure 2 lists the inputs, analyses, criteria and outputs required for integrating BIM and EVM during the planning and execution stages. Each phase has its own group of inputs and outputs. The main inputs in the planning phase are the Work Breakdown Structure (WBS) (related to the 3D BIM model through a Keynote structure), the $3 D$ BIM model, and the duration and cost of the activities. In the execution phase, it is the progress of the work effectively executed and the approved change requirements. 


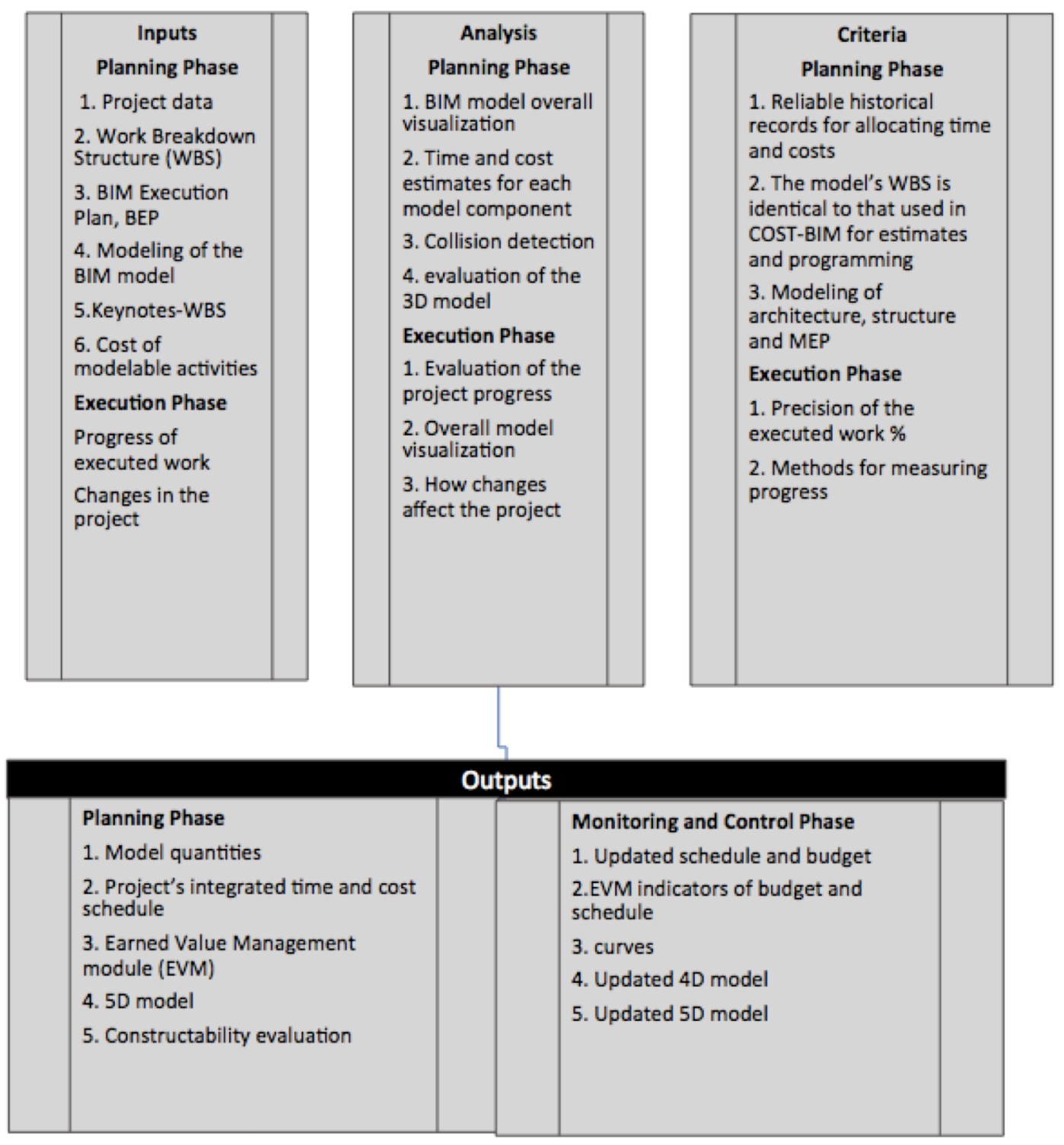

Figure 2. BIM-EVM arquitecture

COST-BIM proposes an efficient system that facilitates the project and management coordination, and improves the communication among stakeholders, thereby ensuring the storage, integration and synchronization of the project data, such as the scope, schedule and budget, in a single BIM-EVM interface.

\subsection{Methodology of the BIM-EVM System}

The BIM-EVM system addresses the planning, execution, tracking and control of a construction project, through its interface, by creating the budget and schedule, EVM indicators and performance curves of any kind of building project, centralized in the project's 3D BIM model and WBS (see Figure 3). 


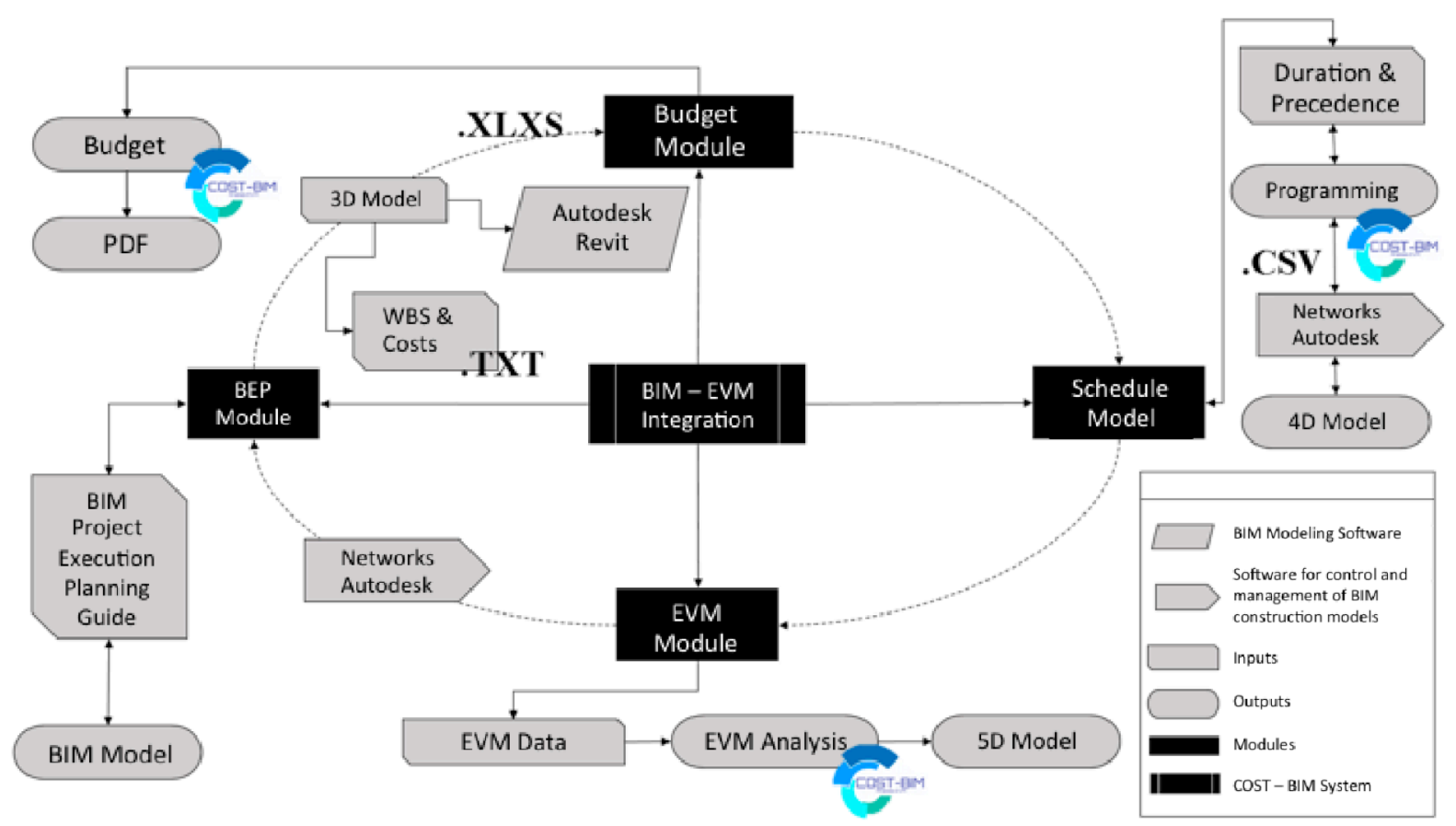

Figure 3. Methodology of the BIM-EVM System

The integration of the BIM-EVM interface with COST$B I M$, requires using the BIM modeling software and a software for the control and management of BIM construction models. In this case, the following was used: BIM modeling software, Autodesk Revit, and Autodesk Navisworks.
However, COST-BIM allows using any BIM software, maintaining certain operability parameters.

Figure 4 describes the integration of BIM and EVM and how it includes the planning, execution, monitoring and control of the project, through the integration of the scope, time and cost management of the project.

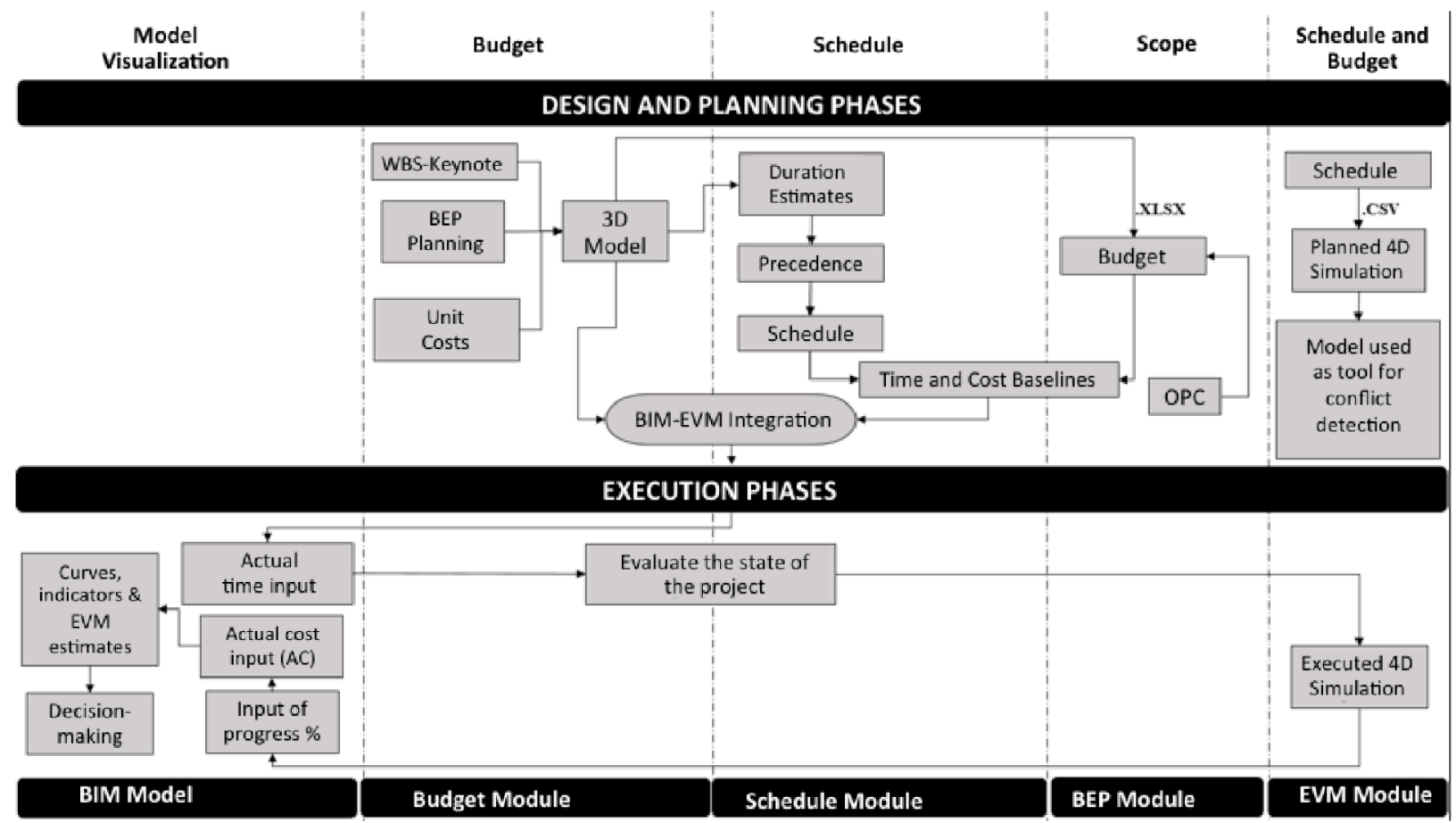

Figure 4. BIM-EVM System during the project's life-cycle 


\section{Results}

COST-BIM was validated to test the viability and potential BIM-EVM integration. The results were corroborated by testing them in two scenarios: during the planning stage and the construction phase. The data analysis and systematization was corroborated according to the system's functionality tests, with data of a real project. As for the validation of the results generated by the software, the COST-BIM budget and schedule was compared against those provided by the partner building company. In order to corroborate the EVM module, it was necessary to develop a Microsoft Excel datasheet, because the building company does not control the schedule nor the budget through EVM.

\subsection{COST-BIM Operation}

The BIM-EVM system is launched by creating the project's WBS in a txt file. Afterwards, the BEP form is issued, which records the persons in charge and the responsibilities associated to the BIM model (see Figure 5).

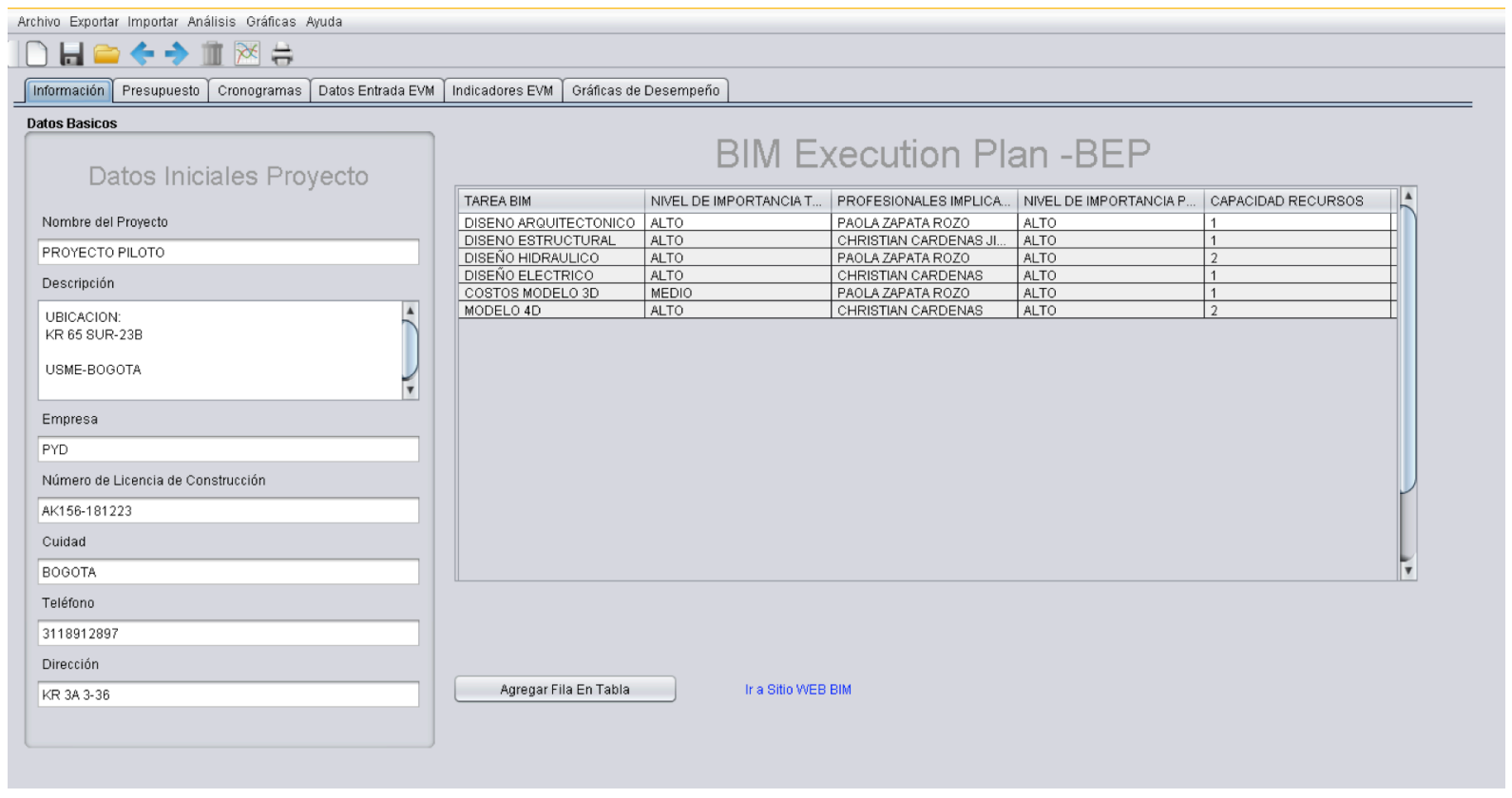

Figure 5. BIM Execution Plan, BEP

The project's WBS is linked through Keynotes. Based on $2 D$ data of the pilot project, the BIM model is run in the modeling software and all the project's relevant data are entered; for example, the cost of each BIM element. The quantities and costs generated in the BIM modeling software are exported from the 3D BIM model to an .xIsx file. This file allows generating the link between COST-BIM and any BIM modeling software. This table contains the following data: 1. Keynote, which classifies the ID of each activity subject to modeling within a project WBS; 2. Level where the element is (this information is important for the configuration of the budget, schedule, EVM and 4D analysis); 3. Physical characteristics of the element (length, height, width, area, volume), which provide the element quantities for the budget; 4. Characteristic of the element to be analyzed. This option is highly relevant, because the unit cost of the element is inserted here, which allows calculating the budget automatically later on.

After the BIM model is completed, the quantities are exported to an .xIsx file, and then they are imported to COSTBIM. The schedule is automatically generated based on the project WBS; the duration is allocated to each activity, based on a Gantt chart, envisaging the logic precedence of the project activities (see Figure 6). 
ENGLISH VERSION

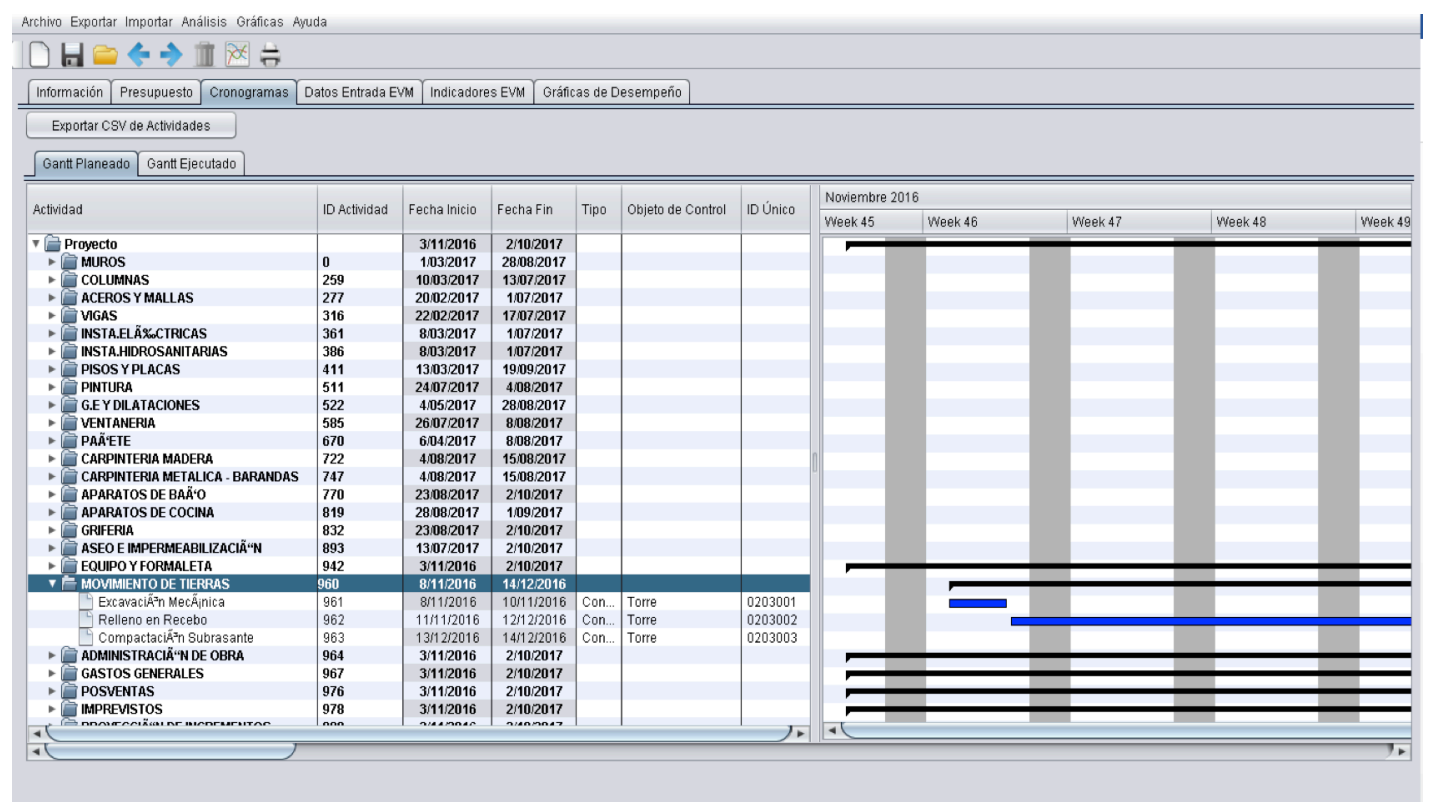

Figure 6. Schedule Module

Finally, a .cvs file is created with the schedule data, in order to import it to the software for control and management of BIM construction models, with the aim of making the $4 D$ simulation.

It is important to mention that, when you import the project quantity .xIsx file to the COST-BIM software, the budget is automatically created according to the project WBS, and simultaneously with the schedule. The budget (see Figure 7) is presented in a 3-level tree structure (chapters, subsubsections, items), with their respective control accounts.
Non-modelable activities are created with their respective costs and the corresponding overhead, profit and contingency (OPC). It should be mentioned that non-modelable activities are automatically created in the schedule; therefore, you have to go back to the schedule and allocate the corresponding precedence and duration. It should also be highlighted that the COST-BIM budget module allows updating the budget automatically, based on the changes made directly on the $3 D$ BIM model, without losing the previously added data.

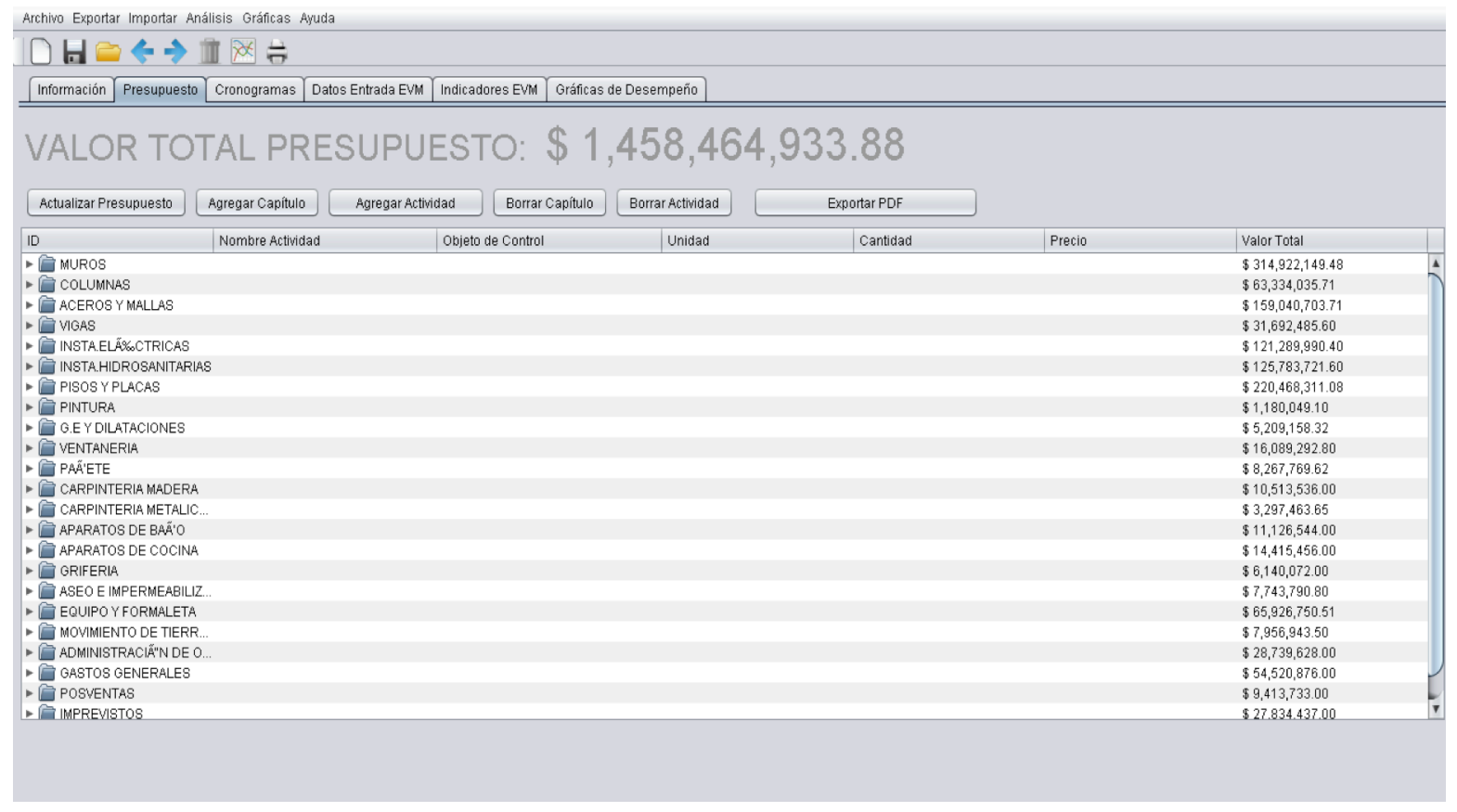

Figure 7. Budget Module 
To conclude, the project's performance is measured through the earned value. The planned and executed data are compiled and processed. Then, you enter the data such as the actual cost AC, and the \% completed to date for each activity (based on the $4 D$ simulation), with the aim of obtaining the performance indicators for the budget and schedule (see Figure 8), together with the EVM charts (see Figure 9).

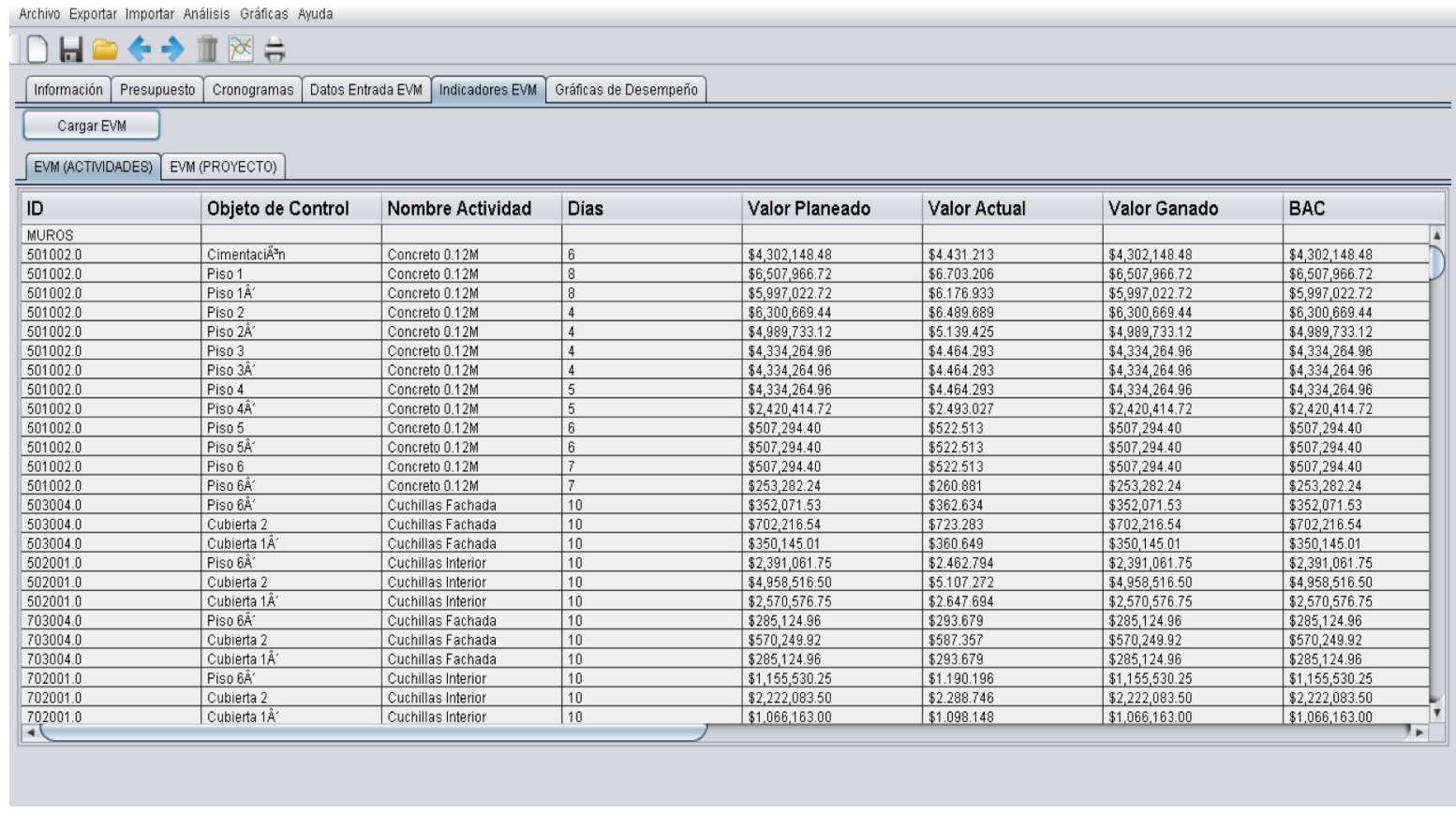

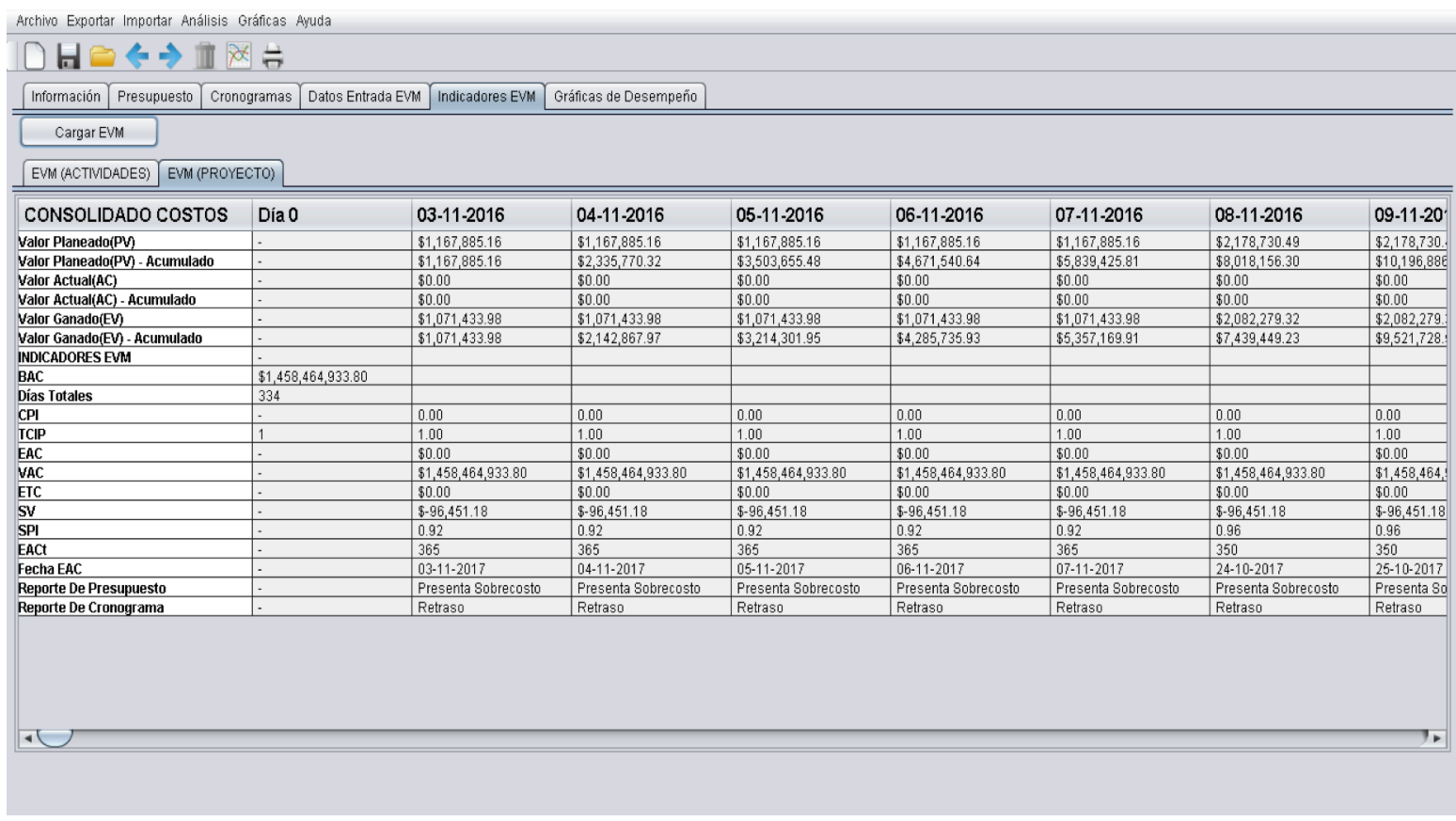

Figure 8. EVM module 

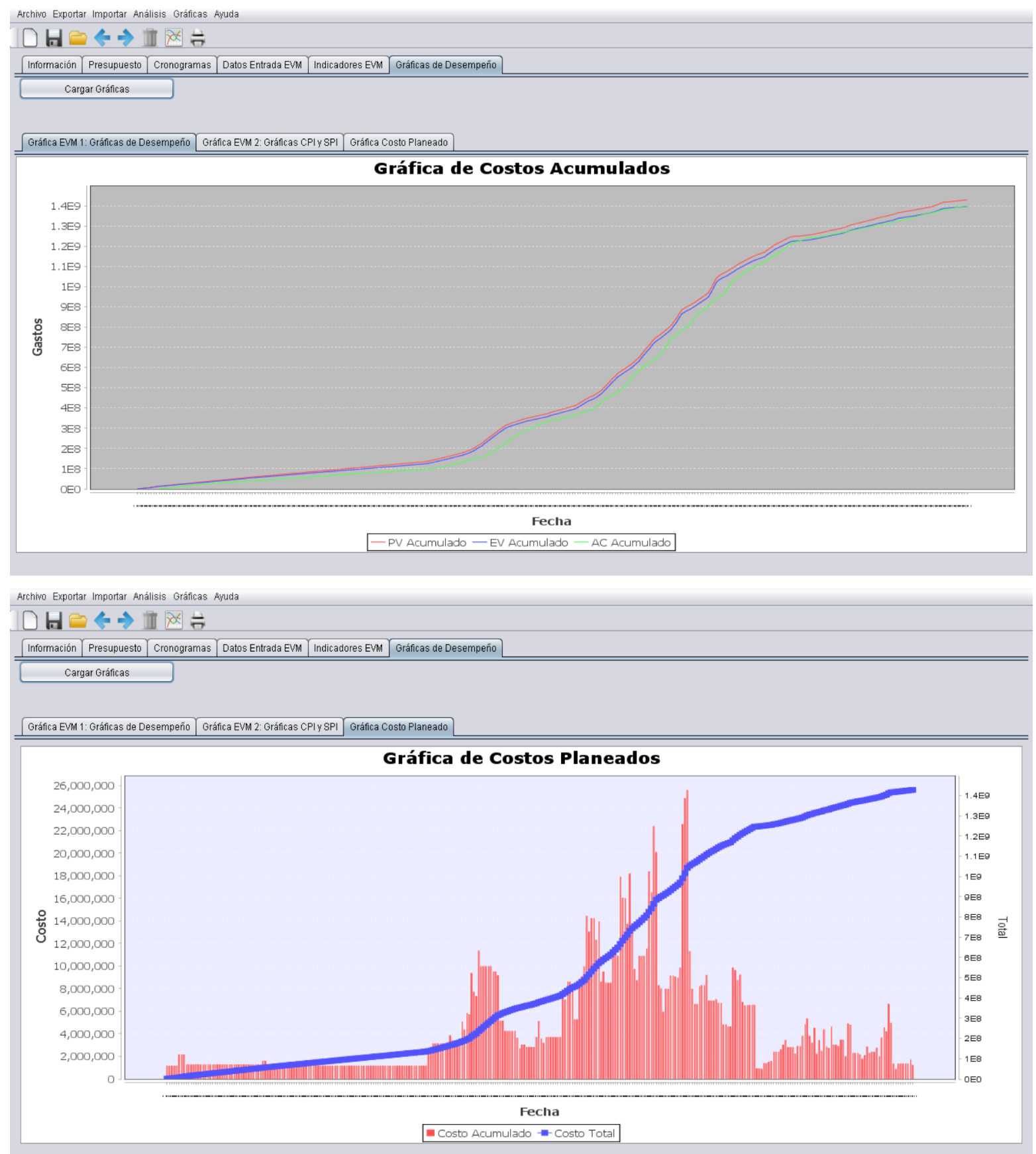

Figure 9. EVM charts module

\subsection{Pilot Project}

The BIM-EVM interface of COST-BIM was validated by a real, social-interest housing project $(\mathrm{SIH})$ located in Usme, Bogota D.C., Colombia. The project consists in 18 towers of 6 floors, 4 apartments per floor, for a total of 432 housing units, whose construction will be completed in 2018. This type of project is composed of iterative modular spaces, which make the modeling process easier, and that is why it was chosen for the validation. The total built area is $23,456 \mathrm{~m}$, which has saleable areas from $47 \mathrm{~m}$ to $61 \mathrm{~m}$. Figure 10 describes the model characteristics. It should be noted that the validation process analyzed the budget and schedule of a double module (2 towers) of 24 apartments from the foundation to the roof, with the aim of simplifying the validation. The budget of this double module is 1,446,108,083.00 and the timeline is 349 days. 

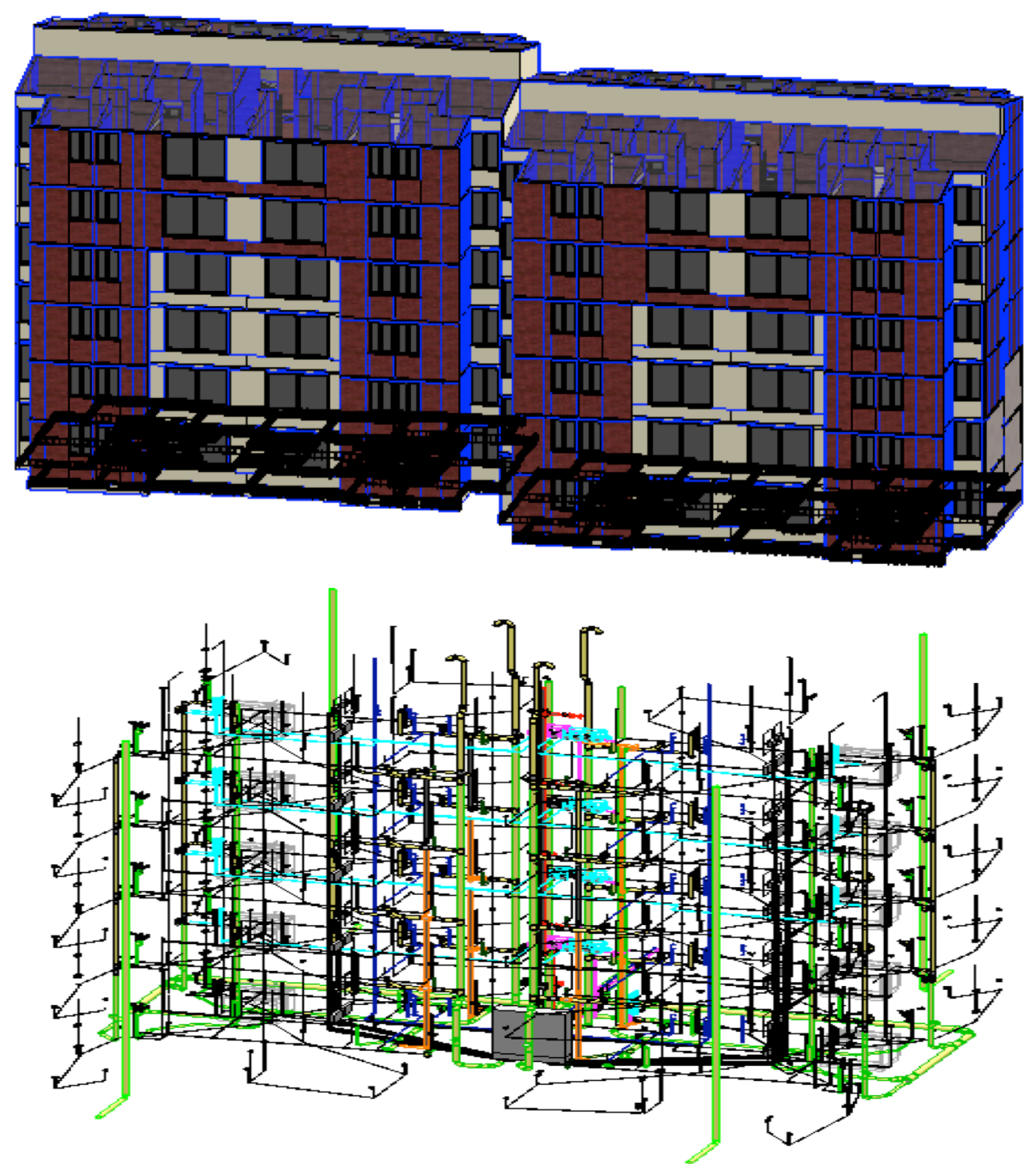

Figure 10. Architectural, Structural and MEP Model 
amount quantification of the BIM-EVM system, which is based on the 3D BIM model. This difference is not significant, because it represents less than $1 \%$ of the original budget. Likewise, the budget generated by COST-BIM fits the project planning.

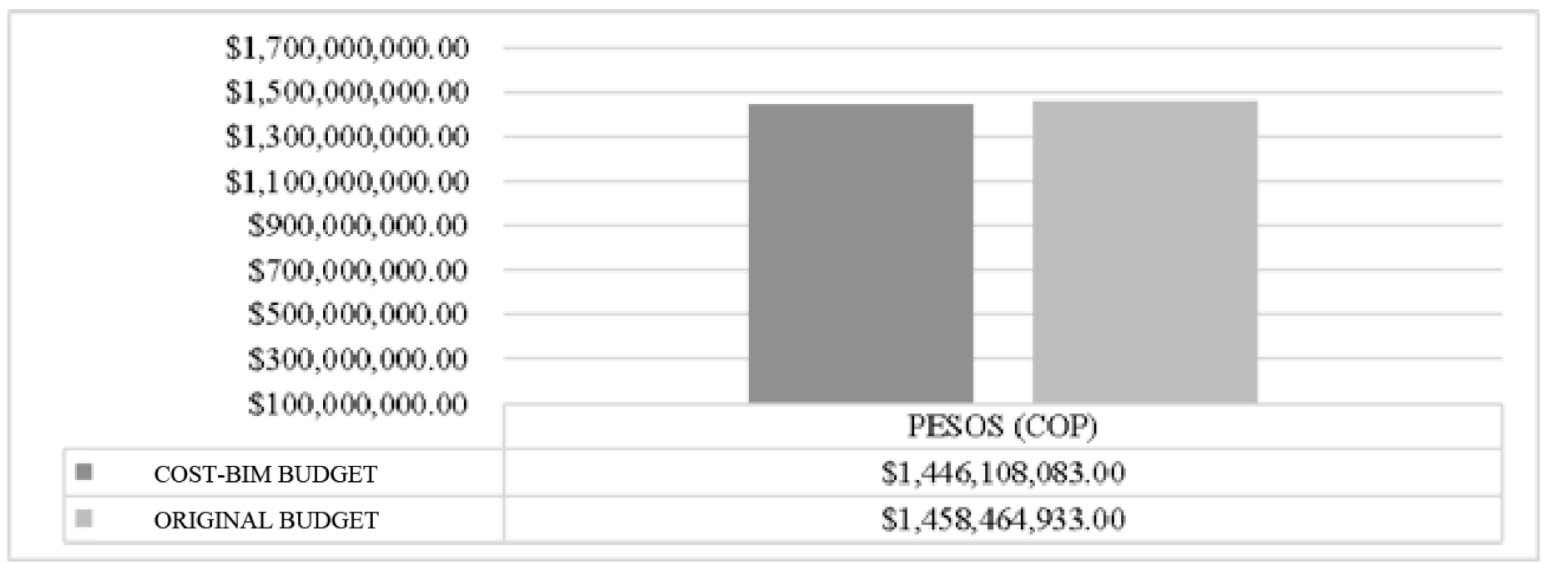

Figure 11. Original Budget vs COST-BIM

Regarding the schedule module, there is a difference of $4.3 \%$ (see Figure 12) in relation to the original schedule. The schedule difference lies in the impossibility of programming the holidays of the Colombian calendar in COST-BIM, an inconvenient that will be solved in the software's future versions. 
DURATION IN DAYS

280

$290 \quad 300 \quad 310$

320

330

340

350

360

DURATION IN DAYS

Figure 12. Original Schedule vs COST-BIM

Concerning the EVM module, the indicators and estimates generated by COST-BIM were identical to those generated by the Microsoft Excel datasheet (see Figure 13).

\begin{tabular}{|c|c|c|}
\hline \multirow[t]{2}{*}{ Cost consolidation } & & EVM Proyect \\
\hline & $10 / 09 / 2017$ & $10 / 09 / 2017$ \\
\hline Planned Value (PV) & $\$ 1,241,979.74$ & $\$ 1,241,979.74$ \\
\hline Accumulated Planned Value (PV) & $\$ 1,428,342,939.65$ & $\$ 1,428,342,939.65$ \\
\hline Actual Cost $(A C))$ & $\$ 1,434,630.12$ & $\$ 1,434,630.12$ \\
\hline Accumulated Actual Cost (AC) & $\$ 1,399,029,279.51$ & $\$ 1,399,028,473.25$ \\
\hline Earned Value (EV) & $\$ 1,078,979.48$ & $\$ 1,078,979.48$ \\
\hline Accumulated Earned Value (EV) & $\$ 1,396,076,094.99$ & $\$ 1,396,076,094.99$ \\
\hline \multicolumn{3}{|l|}{ EVM Indicators } \\
\hline \multicolumn{3}{|l|}{$\mathrm{BAC}$} \\
\hline \multicolumn{3}{|l|}{ TOTAL DAYS } \\
\hline $\mathrm{CPI}$ & 0.75 & 0.75 \\
\hline TCPI & 1.00 & 1 \\
\hline EAC & $\$ 1,939,200,658.74$ & $\$ 1,939,200,658.74$ \\
\hline VAC & $\$-480,735,724.86$ & $\$-480,735,724.86$ \\
\hline ETC & $\$ 1,937,766,028.62$ & $\$ 1,937,766,028.62$ \\
\hline SV & $-\$ 163,000.26$ & $\$-163,000.26$ \\
\hline SPI & 0.87 & 0.87 \\
\hline EACt & 385 & 385 \\
\hline \multirow[t]{3}{*}{ EAC Date } & $23 / 11 / 2017$ & $23 / 11 / 2017$ \\
\hline & & Presents Overrun \\
\hline & & Delay \\
\hline
\end{tabular}

Figure 13. Original EVM vs COST-BIM 
Until the cutoff date of 09/10/2017, the pilot project presents a progress of $75 \%$, a planned value of $P V=$
$\$ 1,428,342,939$, an actual cost of $A C=\$ 1,399,028,473$ and an earned value of $E V=\$ 1,396,076,094$ (see Figure 14).

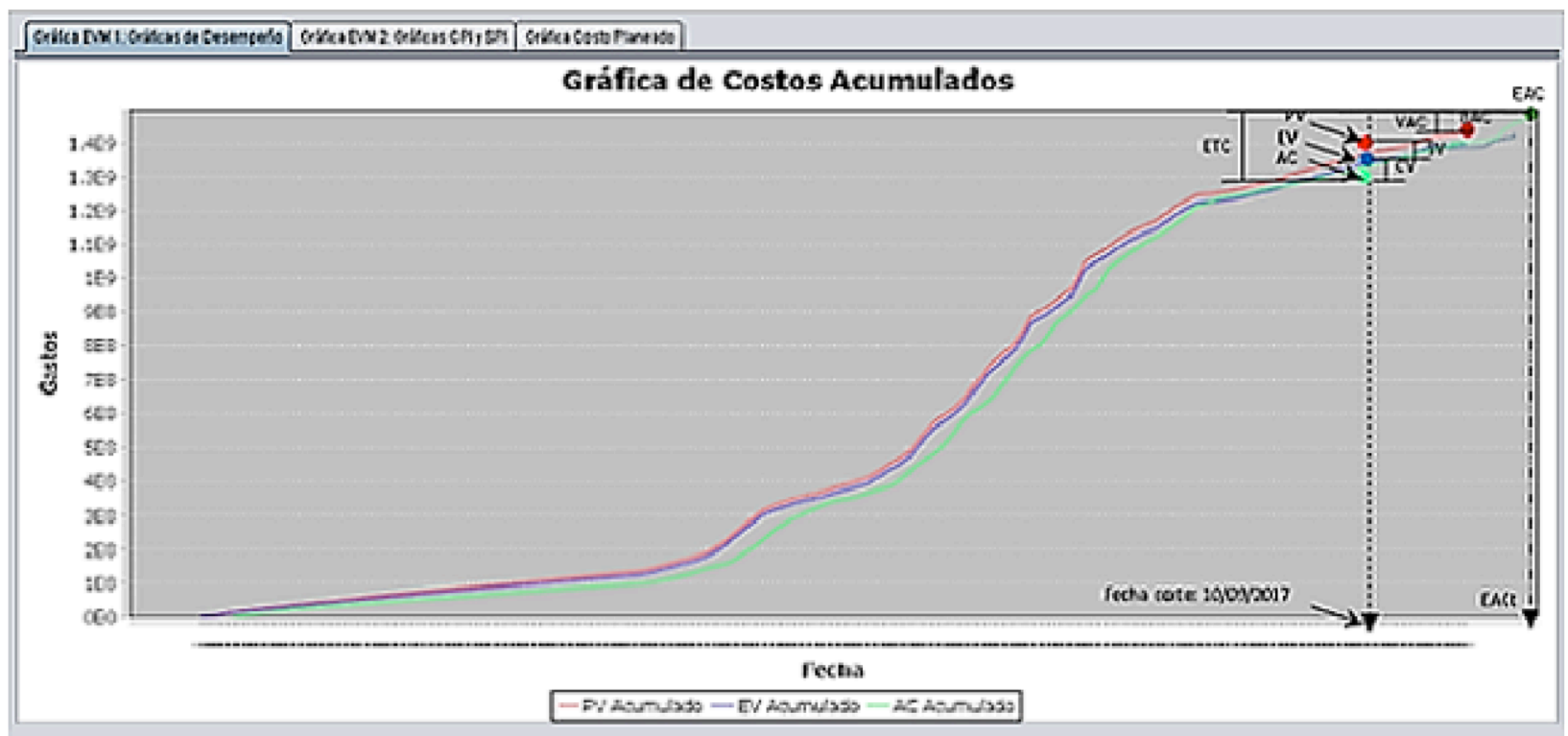

\begin{tabular}{|c|c|c|c|}
\hline \multicolumn{2}{|c|}{ Budget Indicators and Estimates } & \multicolumn{2}{|c|}{ EVM Analysis Inputs } \\
\hline $\mathrm{BAC}, \mathrm{Budget}$ at completion & $\$ 1,458,464,933.00$ & Planned Value (PV) & $\$ 1,428,342,939.65$ \\
\hline CPl, Cost performance index & 0,75 & Actual Cost $(A C)$ & $\$ 1,399,028,473.25$ \\
\hline CV, Cost variance & $-\$ 355,650.64$ & Earned Value EV) & $\$ 1,396,076,094.99$ \\
\hline TCPI, To-complete performance index & 1,0 & & \\
\hline EAC, Estimate at completion & $\$ 1,939,200,658.74$ & & \\
\hline VAC, Variance at completion & $-\$ 480,735,724.86$ & & \\
\hline ETC, Estimate to Complete & $\$ 1,937,766,028,62$ & & \\
\hline \multicolumn{2}{|c|}{ Schedule Indicators and Estimates } & & \\
\hline SPI, Schedule performance index & 0,87 & & \\
\hline SV, Schedule variance & $-\$ 163,000.26$ & & \\
\hline EAC Estimate at completion (time) & 385 days & & \\
\hline Date (EAC) & $23 / 11 / 2017$ & & \\
\hline
\end{tabular}

Figure 14. COST-BIM-generated Indicators, Estimates and Curves 
Based on the information in Figure 14, the budget has a negative performance with a $\mathrm{CPI}=0.75$ lower than 1 , which indicates an inefficient budget investment during the project execution. Thus, the final cost of the project is estimated at $E A C=\$ 1,939,200,658$, showing a variation between the planned budget and the executed budget of VAC $=-\$ 480,735,724$. Regarding the project schedule, it presents delays resulting from the failure to meet the dates predetermined in the planned schedule. The project did not start as planned on 11/03/2016, but on 11/10/2016, thereby causing a one-week delay, due to non-compliance of the earthworks contractor. Subsequently, a two-week delay was produced by a non-compliance of the masonry contractors. Given this scenario, the project schedule presents a negative situation with a SPI $=0.90$ lower than 1 , which indicates a poor performance. Therefore, a duration is estimated of EAC = 385 days instead of 334 days, as established in the planned schedule. Thus, the project will be completed on 11/23/2017 and not on 10/02/2017, as envisaged in the planning.

According to the generated indicators and estimates, COST-BIM forecasts a negative scenario for the pilot project until the cutoff date. Therefore, systems like the one proposed in COST-BIM could mitigate this kind of negative scenario by identifying the project activities causing the variations between the planned and executed schedule and budget.

Consequently, these systems can be a useful tool for construction managers, during the planning and design phase, and gain more relevance during the execution, tracking and control for the decision-making process aimed at changing the course of the project, on the condition that it is implemented since the beginning of the project.

Regarding the pilot project, the implementation of BIM-EVM in the COST-BIM tool demonstrates that it operates as expected and meets the requirements and specifications previously determined, because it generates the necessary alerts to make assertive decisions during the project execution.

\section{Discussion}

Currently, there are different OpenBIM project management software, from 2D BIM to 5D BIM. Researcherslike (Su, Chen and Chien, 2015) developed interoperable CSIS with Autodesk Revit that are able to integrate budget and schedule into a single interface. This tool includes just the planning phase of building projects, because its interface did not develop a cost and time control module. (Jrade and Lessard, 2015) developed ITCMS, which is able to integrate both budget and schedule, adding a time and cost control through the EVM technique. However, the use of different tools for construction project management causes data reprocessing and leaks.

Likewise, the software market aimed at construction project management offers different alternatives. Table 1 lists some of them, and also indicates the weaknesses with regard to COST-BIM and the BIM-EVM system.

Table 1. COST-BIM vs Other Tools

\begin{tabular}{|c|l|}
\hline \multicolumn{1}{|c|}{ Software } & \multicolumn{1}{|c|}{ Disadvantage in relation to COST-BIM } \\
\hline Edificar & $\begin{array}{l}\text { Its interface does not integrate the schedule, thereby generating data reprocessing. It does } \\
\text { not export schedule data automatically from its interface for } 4 D \text { simulations. The EVM is } \\
\text { very broad, it does not calculate the generated indicators by activity. }\end{array}$ \\
\hline Opus-2015 & $\begin{array}{l}\text { It is not OpenBIM, it does not integrate the schedule in its interface, which prevents the } \\
\text { schedule data export for } 4 D \text { simulations. }\end{array}$ \\
\hline SAP & $\begin{array}{l}\text { Its interface does not integrate the schedule. It does not control schedule nor budget } \\
\text { through EVM. }\end{array}$ \\
\hline Microsoft-Project & $\begin{array}{l}\text { It generates data leaks and reprocessing. It does not control schedule nor budget through } \\
\text { EVM. }\end{array}$ \\
\hline Microsoft -Excel & Its interface does not integrate the schedule. It generates data leaks and reprocessing. \\
\hline Presto & $\begin{array}{l}\text { Its interface does not integrate the schedule. It does not control schedule nor budget } \\
\text { through EVM. }\end{array}$ \\
\hline Primavera-PB & $\begin{array}{l}\text { It is not OpenBIM. It does not integrate the schedule in its interface. It does not control } \\
\text { schedule nor budget through EVM. }\end{array}$ \\
\hline Silos-Software & $\begin{array}{l}\text { It does not generate the budget based on the BIM model; therefore, the budget updating } \\
\text { presents data leaks and reprocessing. }\end{array}$ \\
\hline It is not OpenBIM. It does not control schedule nor budget through EVM. \\
\hline It does not control schedule nor budget through EVM. \\
\hline It does not control schedule nor budget through EVM. \\
\hline
\end{tabular}


ENGLISH VERSION

Therefore, it is inferred that COST-BIM reduces the gap found in applications such as ITCMS, CSIS and other software on the market. The advantage of COST-BIM is that it integrates time and cost into a single interface, in the same way as the BIM methodology and the EVM technique, thereby managing projects since their planning and design until their execution, tracking and control in a OpenBIM environment, and controlling the performance of schedules and budgets of construction projects.

\section{Conclusions}

COST-BIM adapts itself to the BIM methodology and gets the best of the benefits of the modeling and control software available in the BIM construction model management, because it allows coordinating and visualizing construction projects, with the aim of associating time and cost to each component of a 5D construction model. Likewise, it adjusts itself and promotes the good practices of the Project Management Institute (PMI), by developing schedules and budgets according to $P M I$ recommendations. Change control within the 3D BIM model and the project performance control in their baselines were also considered, based on the project WBS.

It has the potential to improve the workflow in construction project management and, additionally, the following benefits were identified in its implementation in the project: the capacity to associate detailed values of time and cost of each component of the building model during the planning phase; the automatization of the cost estimate and budget preparation process; the creation of a time and cost baseline, which serves as a reference for an EVM performance analysis in any cutoff date of the project; and the estimate of the possible course of the project, using performance trends to offer the project manager a tentative scenario of the project's future.

The COST-BIM software, together with BIM tools, are bound to improve good construction practices and foster the implementation of the EVM technique and the BIM methodology in the building industry. Moreover, it will help construction managers to make key decisions at the right time during the project planning and execution stage, since this tool offers the possibility to analyze indicators in a overall way (analysis by project) or specifically (analysis by control object, work packs and deliverables), because it analyzes them independently.

In the future, COST-BIM modules could include risk management and quality, since they could be directly related to 5D BIM models; this could help construction managers to efficiently manage their projects.

Furthermore, we recommended that future versions of this management tool are associated to other accounting or cost control tools, in order to process the Actual Costs generated by each deliverable in a more automatized and accurate way, because currently, the user has to insert these costs manually.

\section{References}

Abadie R.; Raymond W.; Morgan A.; Caletka,T. (2013), Correcting the course of capital projects Plan ahead to avoid time and cost overruns down the road. Delaware: PWC network.

Chou J.; Chen H.; Hou C.; Lin, C. (2010), Visualized EVMsystem for assessing project performance. Automation in Construction, 596-607.

Czarnigow A. (2008), Earned value method as a tool for project control. Budownictwo i Architektura, 15-32.

Eastman C.; Teicholz P.; Sacks, R.; Liston K. (2008), BIM Handbook A Guide to Building Information Modeling for Owners, Managers, Designers, Engineers and Contractors. New Jersey : Jhon Wiley\&Sons, Inc.

Enshassi A., Abuhumra L. (2016), Investigación de las funciones del modelado de la información de construcción en la industria de la construcción en Palestina. Revista Ingeniería y Construcción, 127-138.

Hitt M.; Black S; Porter L. (2006), Administración . Mexico D.F: Pearson .

Isaza P.; Botero, F.; Vasquez H. (2015), Estado de la Practica BIM en Colombia. Sibragec Elagec, 1-9.

Jrade A.; Lessard J. (2015), An Integrated BIM System to Track the Time and Cost of Construction Projects: A Case Study. Journal of Cosntruction Engineering, 1-10.

Kim S. (2009), Project success indicators focusing on residential projects: are schedule performance index and cost performance ndex accurate measures in earned value? Canadian Journal of Civil Engineering, 1700-1710.

Messner J. (2010), Project Execution Planning Guide. Pennsylvania: Charles Pankow Foundation and The Pennsylvania State University.

Miyagawa T. (1997), Constructionmanageability planning-a system for manageability analysis in construction planning. Automation in Construction, 175-191.

Project Management Institute. (2005), Practice Standard for Earned alue Management. Pennsylvania: Project Management Institute Inc.

Staub-French S.; Khanzode A. (2007), 3D and 4D modeling for design and construction coordination: issues and lessons learned. Electronic Journal of Information Technology in Construction, 381-407. 
Stevens M. (1986), Cost control: integrated cost/schedule performance. Journal of Management in Engineering, 157-164.

Su L. F.; Chen H. W.; Chien C. H. (2015), Integration of Cost and Schedule Using BIM. Journal of Applied Science and Engineering, $223-232$. 